\title{
Keterkaitan Kegiatan Konsumsi Dan Produksi Beras Dengan Pertumbuhan PDB Di Indonesia Dan Tiongkok
}

${ }^{1}$ Muhammad Fikry Aransyah, Fakultas Ekonomi dan Bisnis (FEB) Universitas Lampung (Unila), Indonesia

\section{Informasi Naskah}

Submitted: 2 Oktober 2019

Revision: 4 November 2019

Accepted: 20 November 2019

Kata Kunci:

Konsumsi beras, Produksi

Beras, $P D B$

\begin{abstract}
Rice is a staple food for most Asian countries, and this can affect their economic performance. The dynamic regression model used in this study to investigate rice consumption or production can explain GDP growth. This research can provide relevant information to several parties such as researchers, academics, and institutions who tend to understand the rice market. This study examines whether rice consumption or rice production has a more considerable influence on the growth of Gross Domestic Product (GDP) in China and Indonesia between the 1990-2015 sample period. Empirical results show that rice production has a more significant influence than rice consumption on GDP growth. The Philips-Perron Root unit test shows that the country's GDP growth shows stationary at the first level and difference. In contrast, Indonesian rice production shows stationary at both levels and the primary difference, the other shows stationary at the first difference. Followed by the Granger causality test and variant decomposition, the results show a two-way relationship on the Chinese causality test.
\end{abstract}




\section{PENDAHULUAN}

Tiongkok dan Indonesia adalah produsen beras dan negara konsumsi teratas. Pada bulan Februari 2016, produksi beras tahunan Tiongkok dan Indonesia adalah 144560 dan 35560 ribu metrik ton(International Rice Research Institute, 2013). Tren peningkatan konsumsi beras per kapita di Asia karena konsumen telah melakukan diversifikasi pola makan mereka dari beras ke makanan bernilai tinggi misalnya, daging, buah-buahan, dan sayuran telah dihentikan oleh negara-negara pertumbuhan ekonomi yang kuat di Asia seperti Tiongkok sejak awal 1990-an. Dari 1992 hingga 2005, konsumsi beras per kapita di Asia menurun dari 103 kilogram menjadi 96 kilogram. Tren penurunan konsumsi beras per kapita telah dibalik dalam beberapa tahun terakhir dan konsumsi per kapita telah mulai meningkat lagi walaupun ada tren penurunan konsumsi per kapita di negara-negara besar seperti Tiongkok dan Indonesia antara tahun 1992 dan 2005.

Alasan pertama ketika memilih Tiongkok dan Indonesia adalah karena masalah kekurangan pangan. Kekurangan pangan adalahmasalah kritis di dunia. Tiongkok telah melaporkan bahwa produksi lokal mereka tidak cukup untuk memenuhi permintaan lokal. Karena itu, negara tersebut mengharuskan impor makanan dari negara lain. Alasan memilih Tiongkok dan Indonesia sebagai sampel karena mereka mewakili negara-negara teratas dalam produksi dan konsumsi beras. Dari sini, menunjukkan bahwa pasar beras memainkan peran penting dalam perekonomian negara-negara ini. Produksi beras dianggap sebagai salah satu kegiatan ekonomi terpenting di dunia dan merupakan sumber pekerjaan dan penghasilan paling penting bagi masyarakat pedesaan dari negara-negara terbelakang (International Rice Research Institute, 2013).

Selanjutnya, penelitian ini menyarankan tolok ukur bagi produsen beras dalam mengambil keputusan. Temuan produksi beras dan konsumsi beras dapat digunakan dalam menentukan harga pasar beras di masa depan. Akibatnya, produsen beras dapat membuat keputusan penetapan harga yang tepat berdasarkan permintaan dari konsumen di pasar. Lebih jauh lagi, hal ini memungkinkan produsen beras untuk memprediksi permintaan beras sehingga selalu ada cukup beras untuk memenuhi pesanan pelanggan dengan waktu memimpin 3 singkat. Koo, Karmana dan Erlandson (1985) mempelajari analisis permintaan beras di Indonesia selama periode 1960-1980. Variabel Independen termasuk harga beras, jagung, dan pendapatan per kapita mengalami kemunduran dengan konsumsi beras tahunan per kapita. Dengan menggunakan pendekatan OLS, hasilnya menunjukkan bahwa ada hubungan positif antara permintaan tahunan beras untuk harga beras dan jagung.

Selain itu, Diao, Hazell dan Thurlow (2010) melakukan beberapa perdebatan dengan menggunakan enam negara yang berlokasi di Afrika, yaitu Ethiopia, Ghana, Kenya, Rwanda, Uganda dan Zambia sebagai sampel mereka. Debat tersebut prihatin tentang peran potensial pertanian dan industri dalam meningkatkan pembangunan ekonomi Afrika dan pengurangan kemiskinan di mana model simulasi ekonomi digunakan. Hasil empiris menunjukkan bahwa pertumbuhan dalam pertanian lebih signifikan dalam pengurangan kemiskinandibandingkan dengan pertumbuhan non-pertanian. Peningkatan 1 persen dalam PDB per kapita tahunan Ethiopia yang dihasilkan dari pertumbuhan pertanian akan menghasilkan penurunan 1,7 persen dalam tingkat kemiskinan di negara itu per tahun, sementara sektor non-pertanian mampu mengurangi tingkat kemiskinan sebesar 0,7 persen. Temuan tersebut konsisten di enam negara pilihan mereka. Hal ini disebabkan sebagian besar rumah tangga yang tinggal di daerah pedesaan bergantung pada kegiatan pertanian sebagai sumber pendapatan utama mereka. Selain itu, warga kota juga mendapat manfaat dari naiknya pertumbuhan pertanian karena kenaikan produksi tanaman akan menurunkan harga pangan. Oleh karena itu, peningkatan produksi beras akan mendorong pertumbuhan ekonomi dan mengurangi kemiskinan. Dengan demikian, secara tidak langsung akan meningkatkan PDB.

Abdullah, Ito dan Adhana (2006) menemukan bahwa peningkatan pendapatan per kapita adalah faktor utama dalam mengurangi konsumsi beras di wilayah Asia. Studi mereka berfokus pada Bangladesh, Tiongkok, India, Indonesia, Myanmar, Filipina, Sri Lanka, Thailand dan Vietnam dengan periode sampel 1967-2004. Naiknya tingkat pendapatan berarti bahwa perekonomian negara itu berkinerja baik. Makanan berkualitas tinggi lebih disukai oleh konsumen. Namun, penurunan ini bisa diimbangi oleh pertumbuhan populasi. Lebih lanjut, 
penulis menyebutkan bahwa ada beberapa negara Asia yang lebih suka mengimpor beras walaupun mereka dapat mencapai swasembada. Alasannya adalah negara mengalokasikan sebagian dari sumber daya produksi mereka untuk kegiatan yang lebih menguntungkan. Dalam jangka panjang, negara-negara Asia ini akan kehilangan salah satu kekuatan vital mereka. Selain itu, Serkan (2012) melakukan penelitian tentang hubungan antara perubahan pendapatan dan konsumsi beras dalam kasus Tiongkok dan India. Dengan menggunakan data 1965-2007, hasil penulis menunjukkan bahwa beras dapat dianggap sebagai makanan mewah atau makanan pokok. Ini menunjukkan bahwa baru-baru ini kedua negara terpilih secara perlahan diklasifikasikan ke dalam makanan mewah berdasarkan preferensi warga negara. Jika merekamenganggap beras sebagai makanan mewah, peningkatan pendapatan akan meningkatkan jumlah yang dikonsumsi, dan sebaliknya.

\section{METODOLOGI PENELITIAN}

Pada bab ini, penelitian ini menyajikan metodologi yang digunakan seperti uji akar unit, model vector autoregressive (VAR), dekomposisi varians, dan uji kausalitas Granger. Untuk penelitian ini, kami menggunakan data deret waktu pertumbuhan PDB per kapita, produksi beras, dan konsumsi beras untuk 2 negara mulai dari 1990 hingga 2015. Kedua negara adalah Tiongkok dan Indonesia. Data untuk produksi dan konsumsi beras dalam metrik ton, oleh karena itu kami menghitung ulang menjadi logaritma alami. Semua data diambil dari Bloomberg Database.

Tabel 1 menunjukkan hasil yang diperoleh dari uji Philips-Perron. Untuk pertumbuhan PDB, baik model konstan maupun model konstan dan tren menunjukkan bahwa semua negara sampelmemiliki hasil stasioner pada level-level tertentu.

Berdasarkan model dengan syarat dan model konstan dengan tren konstan dan deterministik, produksi beras untuk Tiongkok dan Indonesia ditemukan memiliki pergerakan nonstasioner pada level-level. Untuk seri dalam bentuk perbedaan pertama, hasil dari kedua model menunjukkan bahwa produksi beras di Tiongkok dan Indonesia memiliki pergerakan stasioner.

Di sisi lain, untuk konsumsi beras, istilah konstan menunjukkan bahwa Tiongkok hanya diam pada perbedaan pertama. Hasil yang didasarkan pada model dengan istilah konstan menunjukkan bahwa variabel tersebut dalam bentuk level untuk Indonesia adalah stasioner. Karena hasilnya menunjukkan bahwa semua variabel stasioner, uji kointegrasi tidak perlu dilakukan.

\section{HASIL DAN PEMBAHASAN}

\begin{tabular}{|c|c|c|c|c|c|c|}
\hline & \multicolumn{2}{|c|}{ PDB } & \multicolumn{2}{|c|}{ Produksi Beras } & \multicolumn{2}{|c|}{ Konsumsi Beras } \\
\hline & Level & $\begin{array}{c}\text { First } \\
\text { Difference }\end{array}$ & Level & $\begin{array}{c}\text { First } \\
\text { Difference }\end{array}$ & Level & $\begin{array}{c}\text { First } \\
\text { Difference }\end{array}$ \\
\hline Tiongkok & & & & & & \\
\hline Constant & $-3.4686^{* *}$ & $-5.4310^{* * *}$ & - & $-4.7772^{* * *}$ & -1.3520 & -3.1132 ** \\
\hline $\begin{array}{l}\text { Constant and } \\
\text { Trend }\end{array}$ & $-3.5207^{*}$ & $-4.6169 * * *$ & $\begin{array}{l}1.6737 \\
- \\
1.8976\end{array}$ & $-4.8018^{* * *}$ & -1.7878 & -2.9884 \\
\hline Indonesia & & & & & & \\
\hline Constant & $-3.4609 * *$ & $-9.5771^{* * *}$ & - & $-5.8722^{* * *}$ & -3.4344 ** & -2.1571 \\
\hline $\begin{array}{l}\text { Constant and } \\
\text { Trend }\end{array}$ & -3.3691 * & $\begin{array}{l}-11.3134 \\
* * *\end{array}$ & $\begin{array}{l}2.0420 \\
- \\
2.3823\end{array}$ & $-9.1497^{* \star *}$ & -1.9630 & -2.7208 \\
\hline
\end{tabular}

Catatan: ${ }^{* * *},{ }^{* *},{ }^{*}$ Tolak hipotesis nol tentang keberadaan unit root pada tingkat signifikansi $1 \%, 5 \%$ dan $10 \%$ masing-masing.

Sumber : Data Diolah 
Tabel 2.

Hubungan sebab akibat dinamis antara pertumbuhan PDB dan konsumsi beras

\begin{tabular}{|lc|}
\hline & Estimated statistic \\
\cline { 2 - 2 } Tiongkok & \\
PDB $\rightarrow$ Konsumsi Beras & 0.7350 \\
Konsumsi Beras $\rightarrow$ PDB & 2.8696 \\
Indonesia & \\
PDB $\rightarrow$ Konsumsi Beras & 0.0486 \\
Konsumsi Beras $\rightarrow$ PDB & 0.0013 \\
\hline
\end{tabular}

Catatan: "PDB $\rightarrow$ Konsumsi Beras" menunjukkan Granger pertumbuhan PDB menyebabkan konsumsi beras"Konsumsi Beras $\rightarrow$ PDB" menunjukkanGranger konsumsi beras menyebabkan pertumbuhan $P D B$

Sumber : Data Diolah

Sesuai hasil yang ditunjukkan pada Tabel 2, Tiongkok dan Indonesia tidak memiliki hubungan kausalitas Granger antara konsumsi beras dan pertumbuhan PDB dalam dua arah. Di Tiongkok, pola konsumsi telah berubah menjadi berorientasi daging karena peningkatan pendapatan per kapita. Makanan mewah terjangkau oleh konsumen lokal. Oleh karena itu,permintaan beras menurun secara bertahap.

Sedangkan untuk Indonesia adalah importir beras karena konsumsi beras melebihi produksinya. Dapat diketahui bahwa beras hanya untuk memenuhi kebutuhan sehari-hari warga setempat. Itu karena mayoritas penduduk mereka di daerah pedesaan terutama terlibat dalam sektor pertanian. Agar lebih produktif, mereka terutama mengonsumsi beras. Akibatnya, itu tidak membawa pengaruh signifikan pada pertumbuhan PDB.

Tabel 3 menunjukkan hasil dekomposisi varians dari PDB dan konsumsi beras untuk Tiongkok danlndonesia dari tahun 2 hingga 20. Dalam kasus Tiongkok, ini menunjukkan persentase proporsi PDB tertinggi oleh konsumsi beras sebesar 2,5236 persen. Hasil Indonesia rendah dengan sekitar 0,0004 hingga 0,9912 persen. Alasan utama dari temuan ini adalah ukuran populasi antar negara. Tiongkok menunjukkan persentase proporsi yang lebih tinggi karena kedua negara memiliki ukuran populasi yang besar sedangkan Indonesia memiliki ukuran populasi yang lebih kecil. Lebih jauh, itumenunjukkan bahwa beras adalah makanan pokok Tiongkok karena budaya berasnya untuk waktu yang lama. Selain itu, Tiongkok menunjukkan persentase tertinggi dari proporsi konsumsi beras oleh PDB yaitu 30,8354 persen dan diikuti oleh Indonesia dengan proporsi masing-masing 4,1018 persen. Tiongkok menunjukkan persentase proporsi tertinggi di antara negara-negara ini karena faktor ekonomi dan budaya yang unik membuat limbah makanan di Tiongkok.

Tabel 3:

Hasil Dekomposisi Varians dari PDB dan Konsumsi Beras

\begin{tabular}{ccccccc}
\hline & \multicolumn{3}{c}{ Byinnovationsin } \\
\cline { 2 - 7 } & $\begin{array}{c}\text { Horizon } \\
\text { (Tahun) }\end{array}$ & PDB & $\begin{array}{l}\text { Konsumsi } \\
\text { Beras }\end{array}$ & PDB & $\begin{array}{l}\text { Konsumsi } \\
\text { Beras }\end{array}$ \\
\hline $\begin{array}{c}\text { Tiongkok } \\
\text { PDB }\end{array}$ & 2 & 1.000 .000 & 0.0000 & Konsumsi Beras & 259.057 & 740.943 \\
& 4 & 981.515 & 18.485 & & 277.931 & 722.069 \\
& 6 & 975.468 & 24.532 & 303.818 & 696.182 \\
& 8 & 974.777 & 25.223 & 308.174 & 691.826 \\
10 & 974.768 & 25.232 & 308.356 & 691.644 \\
& 12 & 974.767 & 25.233 & 308.345 & 691.655 \\
& 14 & 974.765 & 25.235 & 308.352 & 691.649 \\
& 16 & 974.764 & 25.236 & 308.354 & 691.646 \\
& 18 & 974.764 & 25.236 & 308.354 & 691.646 \\
& 20 & 974.764 & 25.236 & 308.354 & 691.646 \\
\hline
\end{tabular}

Jurnal Ekonomi Pembangunan, 8 (3) 2020, 183-190. 


\begin{tabular}{|c|c|c|c|c|c|c|}
\hline \multirow{2}{*}{\multicolumn{2}{|c|}{$\begin{array}{ll}\text { Horizon } \\
\text { (Tahun) }\end{array}$}} & \multicolumn{5}{|c|}{ Byinnovationsin } \\
\hline & & PDB & $\begin{array}{l}\text { Konsumsi } \\
\text { Beras }\end{array}$ & & PDB & $\begin{array}{l}\text { Konsumsi } \\
\text { Beras }\end{array}$ \\
\hline \multicolumn{7}{|c|}{ Indonesia } \\
\hline GDP & 2 & 999.978 & 0.0022 & Riceconsumption & 41.018 & 958.982 \\
\hline \multirow[t]{9}{*}{ PDB } & 4 & 999.913 & 0.0087 & & 39.843 & 960.157 \\
\hline & 6 & 999.885 & 0,095833333 & & 39.397 & 960.603 \\
\hline & 8 & 999.826 & 0,120833333 & & 39.185 & 960.815 \\
\hline & 10 & 999.802 & 0,1375 & & 39.069 & 960.931 \\
\hline & 12 & 999.786 & 0,148611111 & & 39.000 & 961.000 \\
\hline & 14 & 999.775 & 0,15625 & & 38.957 & 961.043 \\
\hline & 16 & 999.768 & 0,161111111 & & 38.930 & 961.070 \\
\hline & 18 & 999.763 & 0,164583333 & & 38.912 & 961.088 \\
\hline & 20 & 999.759 & 0,167361111 & & 38.900 & 961.100 \\
\hline
\end{tabular}

Sumber : Data Diolah

Tabel 4:

Hasil uji Kausalitas Ganger antara PDB dan produksi beras

\begin{tabular}{|lc|}
\hline & Estimated statistic \\
\cline { 2 - 2 } Tiongkok & \\
PDB $\rightarrow$ Produksi Beras & $4.0768^{*}$ \\
Produksi Beras $\rightarrow$ PDB & $5.7705^{* *}$ \\
Indonesia & \\
PDB $\rightarrow$ Produksi Beras & 0.0947 \\
Produksi Beras $\rightarrow$ PDB & 0.0020 \\
\hline
\end{tabular}

Catatan: "PDB $\rightarrow$ Produksi Beras" menunjukkan Granger pertumbuhan PDB menyebabkan produksi beras

"Produksi Beras $\rightarrow$ PDB" menunjukkanGranger produksi beras menyebabkan pertumbuhan PDB

**, * Tolak hipotesis nol tentang tidak adanya kausalitas Granger pada level 5\%, $10 \%$ masing-masing

Sumber : Data Diolah

\section{Hubungan sebab akibat yang dinamis antara pertumbuhan PDB dan produksi beras}

Tabel 4 menunjukkan hasil kausalitas Granger antara PDB dan produksi beras. Ada dua cara kausalitas telah ditunjukkan yaitu produksi beras Granger menyebabkan PDB dan GDP Granger menyebabkan produksi beras.

Berdasarkan pada hasil Tabel 4, hanya ada Tiongkok yang memiliki hubungan kausalitas Granger antara pertumbuhan PDB dan produksi beras. Di Tiongkok, produksi beras dan pertumbuhan PDB menunjukkan hubungan kausal dua arah. Temuan ini menunjukkan bahwa produksi beras terdiri dari informasi masa lalu yang berguna untuk memprediksi pertumbuhan PDB di masa depan dengan dua cara.

Karena ada beberapa kebijakan yang telah diterapkan olehpemerintah Tiongkok, kebijakan tersebut termasuk subsidi mesin yang disediakan oleh pemerintah Tiongkok. Kebijakan-kebijakan ini membantu meningkatkan volume produksi beras untuk mendorong pertumbuhan ekonomi. Oleh karena itu, Granger menyebabkan hubungan antara produksi beras dan pertumbuhan PDB ada di Tiongkok.

Namun, tidak ada hubungan kausalitas Granger yang ditemukan di Indonesia. Karena Indonesia adalah importir beras bersih, sebagian besar produksi beras di negara ini digunakan untuk memenuhi konsumsi lokal mereka. Sementara Indonesia, negara ini telah mengkonversi banyak lahan subur menjadi tujuan non-pertanian dan mengakibatkan total output turun. 
Dari Tabel 5, hasilnya menunjukkan bahwa Tiongkokmemiliki persentase lebih besar dari produksi beras mereka dalam menjelaskan pertumbuhan PDB mereka di antara lima negara. PDB Tiongkok dapat dijelaskan oleh produksi berasnya sekitar 12,7717 persen dan memiliki kesenjangan yang besar dibandingkan dengan negara lain. Kesenjangan antaraTiongkok dengan mereka adalah sekitar 10 persen. Tiongkok memiliki persentase tinggi karena mereka padat penduduk, cuaca yang cocok, dan tanah subur dibandingkan dengan negara lain. Namun, para petani Tiongkok juga fokus pada pengembangan padi hibrida untuk meningkatkan produksi beras.

Tabel 5:

Hasil dekomposisi varians dari PDB dan produksi Beras

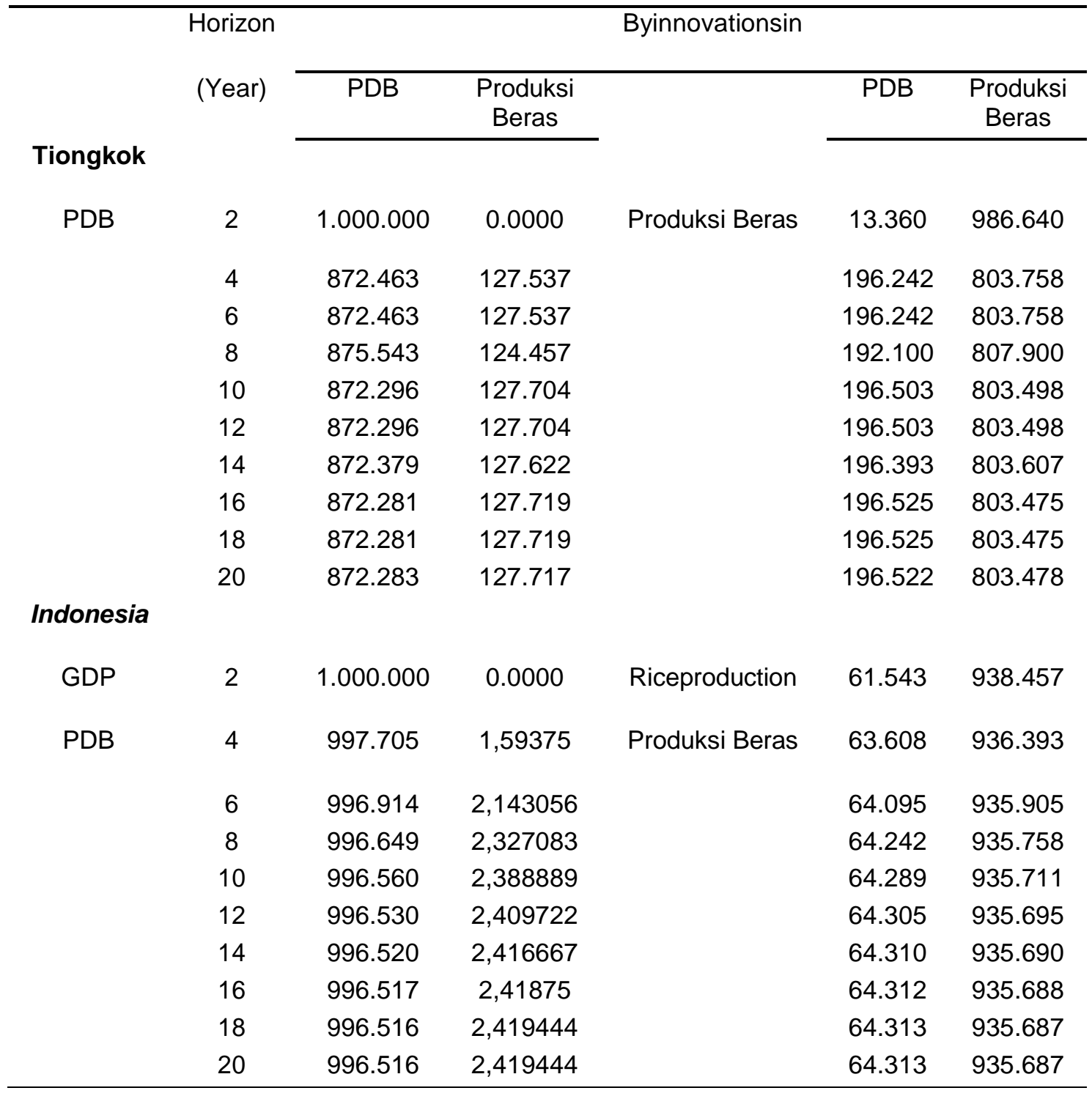

Sumber : Data Diolah

Selain itu, hasil pada Tabel 5 menunjukkan persentase produksi beras dapat dijelaskan oleh PDB. Tiongkok masih menikmati persentase besar di antara lima negara. Karena kinerja ekonomi Tiongkok stabil daripada negara-negara terpilih lainnya, makaTiongkok dapat berinvestasi lebih banyak dalam pengembangan padi hibrida. Tiongkok saat ini sedang menyelidiki padi hibrida generasi kelima. Dari hasil yang diperoleh, dapat ditunjukkan bahwa jika ada kausalitas Granger, akan ada efek limpahan antara variabel; Namun,jika tidak ada kausalitas Granger, mungkin ada efek limpahan.

Ada dua temuan utama berdasarkan kausalitas Granger dan dekomposisi varians. Untuk 
menjawab pertanyaan penelitian sejauh mana konsumsi beras berkontribusi terhadap pertumbuhan ekonomi negara-negara sampel, temuan pertama menunjukkan bahwa konsumsi beras Vietnam Granger menyebabkan pertumbuhan PDB. Namun, hasil penguraian varian menunjukkan bahwa ada efek limpahan untuk Tiongkok dan Indonesia.

Untuk menjawab pertanyaan penelitian sejauh mana produksi beras mempengaruhi pertumbuhan ekonomi, temuan kedua menunjukkan bahwa ada dua arah Granger yang menyebabkan hubungan antara pertumbuhan PDB dan produksi beras di Tiongkok, tetapi produksi beras memiliki pengaruh yang lebih kuat terhadap pertumbuhan PDB. Pertumbuhan GDP yang ditemukan Granger menyebabkan produksi beras di Vietnam. Selain itu, ada efek limpahan antara pertumbuhan PDB dan produksi beras untuk Tiongkok dan Indonesia.

Secara keseluruhan, kedua temuan menunjukkan bahwa PDB Tiongkok dan Indonesia tidak bergantung pada pasar beras untuk pertumbuhannya. Tiongkok tidak fokus pada sektor pertanian untuk PDB mereka tetapi berfokus pada sektor jasa dan manufaktur. Di Indonesia, sektor pertanian berkontribusi besar terhadap PDB mereka.Namun, tanaman utama yang menjadi fokus Indonesia adalah minyak kelapa sawit dan karet. Oleh karena itu, tidak ada kausalitas Granger antara pertumbuhan PDB dan konsumsi dan produksi beras. Selain itu, Tiongkok, dan Indonesia memiliki efek limpahan untuk konsumsi beras dan produksi beras dengan pertumbuhan PDB karena populasi mereka yang besar. Karena populasinya besar, konsumsi beras akan tinggi dan produksinya juga akan meningkat untuk memenuhi permintaan lokal, yang pada gilirannya menyebabkan efek limpahan.

\section{KESIMPULAN DAN SARAN}

\section{Kesimpulan}

Temuan ini menunjukkan bahwa produksi dan konsumsi beras dari Indonesia dan Tiongkok akan mempengaruhi pertumbuhan PDB-nya. Di sisi lain, pemerintah harus menerapkan kebijakan beras untuk mengendalikan konsumsi beras dan impor beras. Konsumsi akan bergeser ke produk pengganti ketika harga ke konsumen meningkat. Oleh karena itu, pemerintah disarankan untuk mengurangi subsidi beras kepada konsumen dan mengenakan pajak impor beras untuk mengurangi konsumsi beras yang tinggi.Keterbatasan yang dapat ditemukan dalam penelitian ini adalah data yang dikumpulkan untuk pertum-buhan PDB didasarkan pada basis keseluruhan dan tidak dipisahkan menjadi sektor primer, sekunder dan tersier yang masingmasing mewakili bahan baku, manufaktur dan jasa.

\section{Saran}

Karena keterbatasan data yang dikumpulkan untuk pertum-buhan PDB didasarkan pada basis keseluruhan dan tidak dipisahkan menjadi sektor primer, sekunder dan tersier yang masingmasing mewakili bahan baku, manufaktur dan jasa, hasilnya tidak informatif karena tidak dapat menjelaskan jumlah konsumsi dan produksi beras yang berkontribusi pada masing-masing sektor. Berdasarkan batasan tersebut, para peneliti menyarankan untuk membagi PDB menjadi tingkat terpilah berdasarkan sektor primer, sekunder, dan tersier. Dengan membagi PDB menjadi tiga sektor, hasil yang diperoleh bisa lebih informatif.

\section{DAFTAR PUSTAKA}

Chung, B. H. and Tan, J. R. (2015). Time series analysis of factors affecting the demand for local rice in Malaysia. International Food Research Journal, 22(5),1870-1877.

International iceResearchInstitute, (2013). RiceAlmanac, 4thedition. Retrieved from http://ricepedia.org/

Koo,W.W., Karmana, M. H., Erlandson, G.W., (1985, July).Analysisof Demand and Supplyof

RiceinIndonesia. Retrieved 22 January2016,from

http://ageconsearch.umn.edu/ bitstream/ 23419/1/aer202.pdf 
Diao, X., Hazell,P., \&Thurlow,J. (2010).TheRole of Agriculture in African Development. World Development, 38(10), 1375-1383.

Abdullah,A.B.,Ito, S., \&Adhana,K. (2006, March). Estimate ofriceconsumption inAsian countries and the world towards 2050. In ProceedingsforWorkshop and Conferenceon Ricein theWorld at Stake,2, 28-43.

Serkan GÜRLÜK.(2012). Convergenceimpacts of two growingAsiancountries on rice consumption:The caseofIndia and China.ScientificResearch and Essays,7(17), 1709171 